\title{
THE RELATIONSHIP BETWEEN INTERNET USAGE AND NEWSPAPER CIRCULATION
}

\author{
Stephen Moran, Neumann University \\ Ryan Savitz, Neumann University
}

dx.doi.org/10.18374/IJBS-13-3.4

\begin{abstract}
The transmission of news and current events is an ever evolving process. One staple mode of media has been the newspaper. In recent years, the internet has become a growing source of information for news and current events. The relationship between internet usage and newspaper circulation is examined in this paper. When controlling for population trends, it is found that a statistically significant, negative relationship exists between internet usage and newspaper circulation. The economic implications of this relationship for the print news industry are also analyzed.
\end{abstract}

Keywords: internet usage, newspaper circulation, variable cost model 